\title{
PERFORMANCE COMPARISON OF LLCC RESONANT BASED MULTI OUTPUT CONVERTER AND SINGLE INDUCTOR BOOST BASED MULTI OUTPUT CONVERTER FOR LED DRIVER APPLICATIONS
}

\author{
Santhi Mary Antony A \\ Assistant Professor, \\ Department of Electrical and Electronics Engineering, \\ Sathyabama University, Chennai -119 . \\ msanthimary@gmail.com
}

\begin{abstract}
The comparison of single-inductor boost based multi output LED driver and charge exchanging and balancing capacitors based multi output LED driver is proposed in this paper. The output dc current is distributed uniformly to all output channels using equal conduction time of each output in first method. In second method the output current is distributed using primary exchanging (inductor and capacitor (LLC)) and balancing capacitor in secondary side. Both circuit operations are discussed. The circuit is simulated using matlab. The performance of the circuit is compared and verified from simulation results.
\end{abstract}

Keywords: LED, LLCC resonant converter, single inductor boost and ZVS

\section{INTRODUCTION}

Now a day's high-brightness LED (HBLED) mostly used in many applications, such as street lighting, automobiles and backlighting, for its low power consumption, long lifetime etc. The individual LED module maximum current rating is limited by thermal management and packaging technology. Focus light, street light applications require a large number of LED's in a single system to achieve high brightness [Y.K. Cheng et al, 2006, M. Krames et al, 2007]. The luminance is determined from LED forward current, as a result each LED has equal current for the same luminance [Yan-Cun Li et al,2012]. The series connection of LED gives balance current sharing, but it requires high bus voltage and less reliability. To overcome this problem LED's are connected in parallel [C. Chen et al, 2007]. But in this method, current sharing is a challenge work. Different topologies are developed for equal current sharing of multi output LED string [H. Chiu et al, 2007, Y.Hu et al 2008, S. Li et al 2012]. These topologies give more power loss. The light brightness mainly depends on current not in voltage. The current balance mechanism is very important [Y. Hu et al 2008, Hyun-Chang Kim et al 2014]. In this paper, two different topologies are discussed for multi output LED's. First circuit LLCC resonant inverter based multi output LED driver. In this circuit the primary LLC and secondary balancing capacitor is used to distribute the uniform current for each channels [Xinke Wu et al,2015]. Second circuit single inductor boost based multi output converter. In this circuit the output current is distributed uniformly with help of equal time sharing concept [Hyun-Chang Kim et al,2014]. Both circuit performances are compared with simulation results. From simulation results will find the best circuit.

\section{Conventional Circuit operation}

Fig 1 shows the LLCC resonant inverter based three-output LED driver Circuit diagram. It consists DC source, half bridge resonant inverter, high frequency step down inverter and multi output rectifier. The resonant converter is used to convert de to high frequency ac with sinusoidal form. This output current has lower harmonics. The inverter output is given to step down transformer. The high switching frequency reduces the transformer size and conduction loss. The output side rectifiers convert ac to dc and drive the LED lights. The primary LLC and secondary side balance capacitor (C) are used to maintain uniform current sharing, as a result each output of all LED's flow equal brightness. 


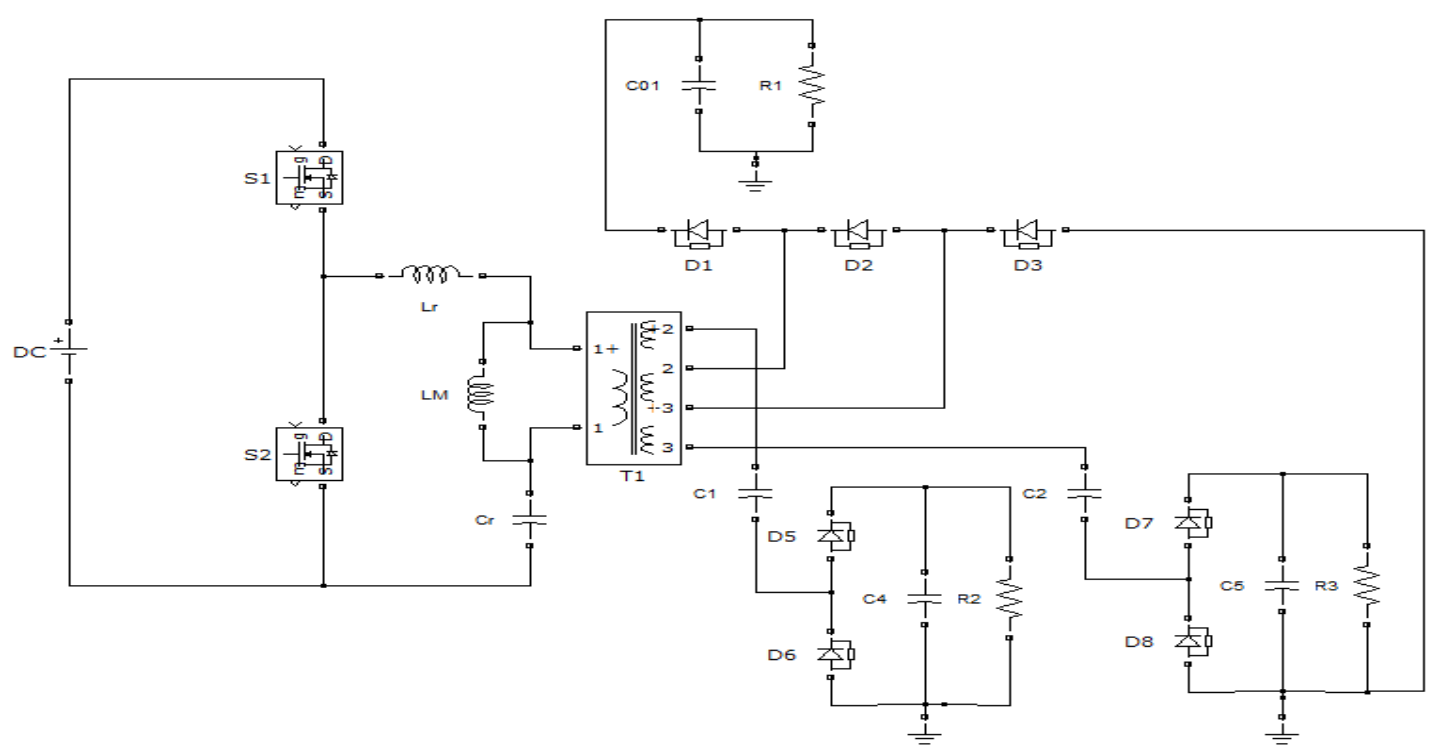

Fig. 1. LLCC resonant inverter based three-output LED driver Circuit diagram

\section{Mode 1 [t0-t1]:}

Fig 2a shows the mode-1 operation during this time $\mathrm{S} 1$ is turn on in primary side and D1, D3, D6,D7 becomes forward biased in secondary side. The current flow as shown in fig 2a. The primary capacitor $\mathrm{C}_{\mathrm{r}}$ and inductance $\mathrm{L}_{\mathrm{r}}$ resonant with secondary side capacitors $\mathrm{C} 1$ and $\mathrm{C} 2$. This mode ends when primary switch M1 turns off at $\mathrm{t} 1$.

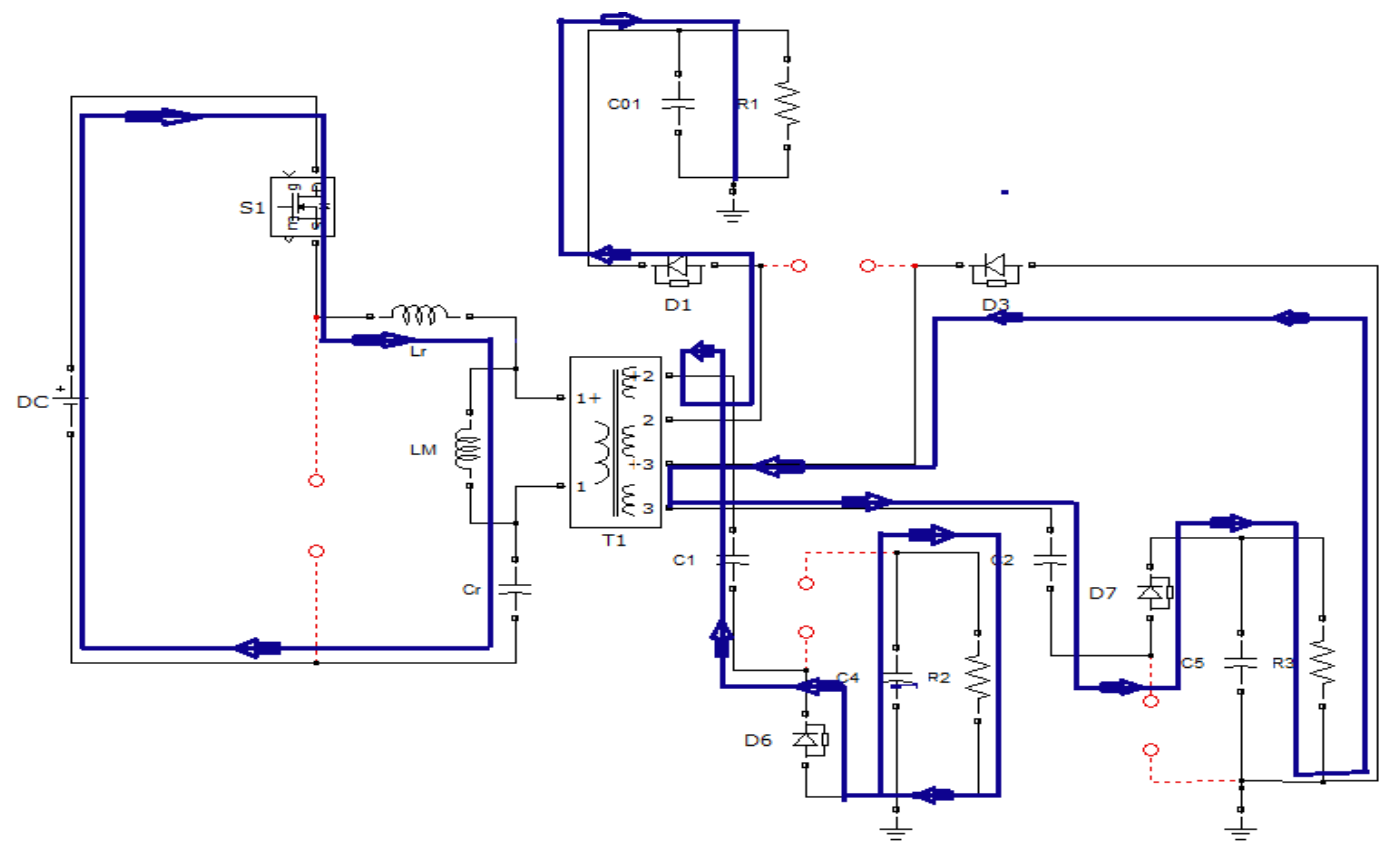

Fig. 2. Modes of operation, 2a) Mode 1

\section{Mode 1 [t0-t1]:}

Fig 2a shows the mode-1 operation during this time S1 is turn on in primary side and D1, D3, D6,D7 becomes forward biased in secondary side. The current flow as shown in fig 2a. The primary capacitor $\mathrm{C}_{\mathrm{r}}$ and inductance $\mathrm{L}_{\mathrm{r}}$ resonant with secondary side capacitors $\mathrm{C} 1$ and $\mathrm{C} 2$. This mode ends when primary switch $\mathrm{M} 1$ turns off at $\mathrm{t} 1$.

Mode 2 [t1-t2]:

After t1, because the diodes D1, D3, D5 and D6 are still on, the resonant inductance $\mathrm{L}_{\mathrm{r}}$ charges the intrinsic capacitances of M1 and M2 during this interval. The equivalent circuit of this mode is shown in Fig. 2(b). This mode ends when the voltage vds across M1 reaches Vin. Similarly, next half cycle also conduct with corresponding switch and diode combination. 


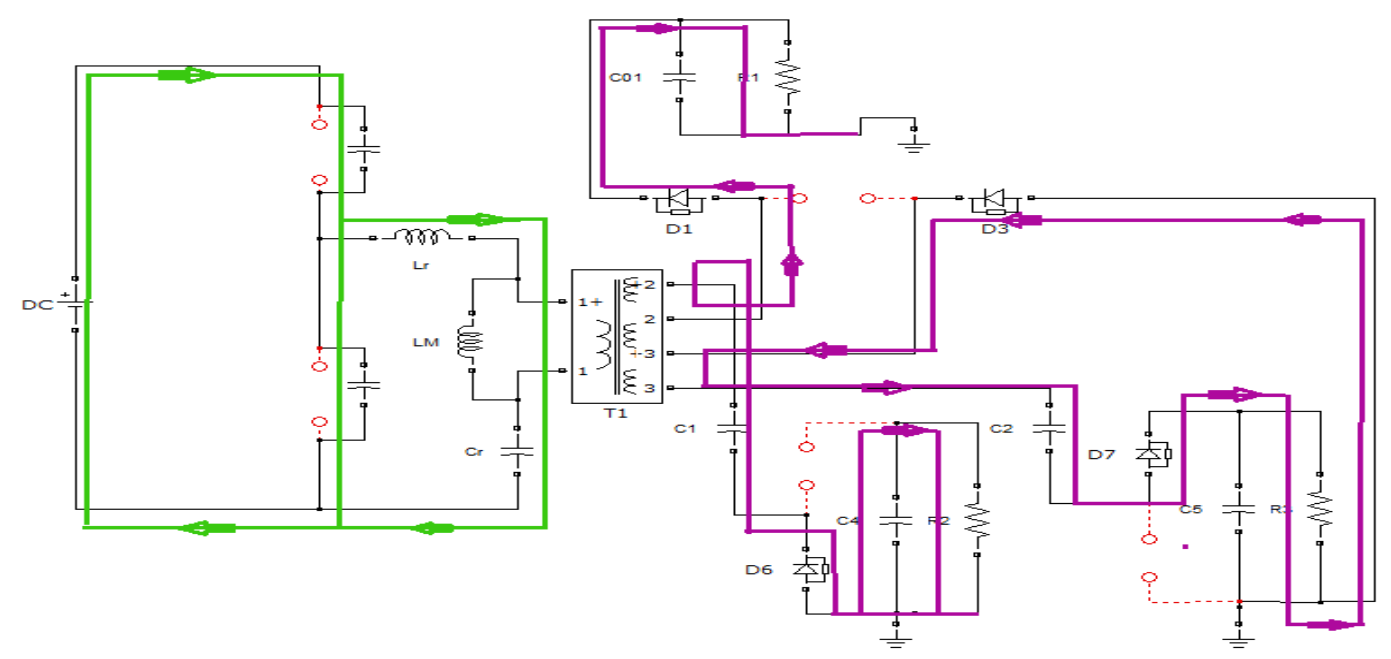

Fig. 2. Modes of operation, 2b) Mode 2

\section{Proposed Circuit operation}

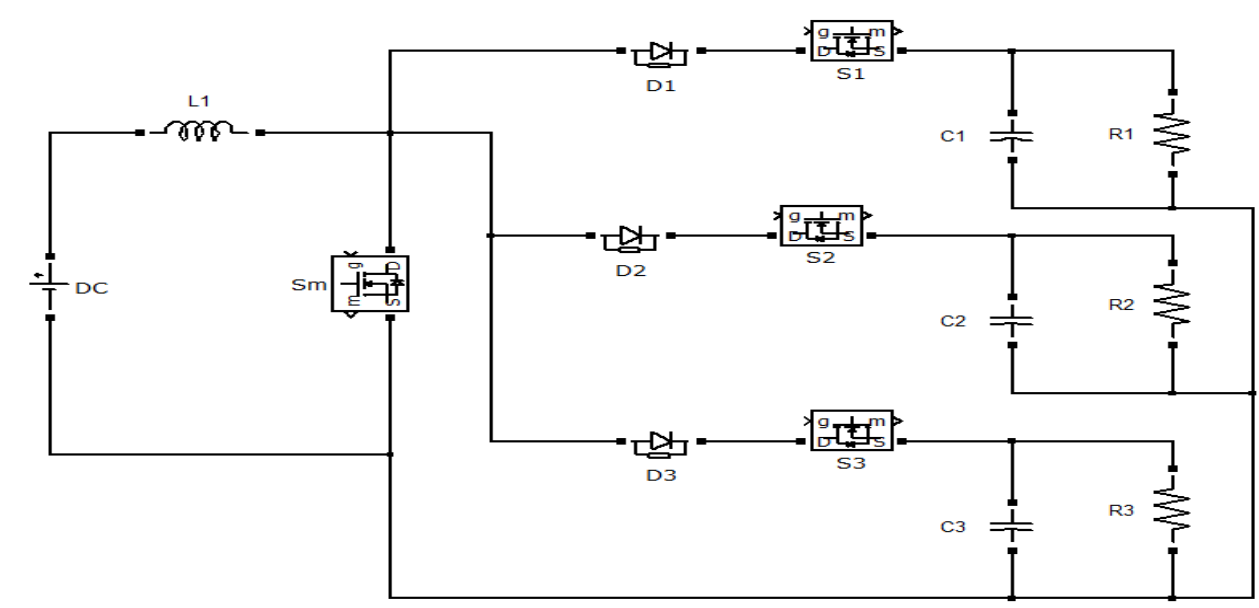

Fig. 3. Circuit diagram of single inductor boost based three-output LED driver Circuit diagram

Fig 3 shows the single inductor boost based three-output LED driver circuit diagram. This circuit consists of boost converter and multiple output section. The output current is controlled by controlling the series switch. When the low-side switch SM turns on, the input source energy is charged onto the inductor $\mathrm{L}_{1}$. The on-period of this switch is controlled by a feedback loop to achieve the desired level of total LED current. Next, the highside switches S1, S2, S3 turn on sequentially, connecting the charged inductor to each LED channel one at a time and for a fixed period of time. If the average current through the inductor is IL1 and the duty cycle of each channel being connected is D, the voltage across each LED channel, i.e., VOUT1, VOUT2, VOUT3, will then settle to the value that makes its average current equal to IL1. D, ignoring the current and voltage ripples within the switching period. Therefore, the SIMO boost converter in this work operates in a continuous conduction mode (CCM) and drives multiple channels within one switching period. The fig 4 shows the modes of operation of the proposed converter.

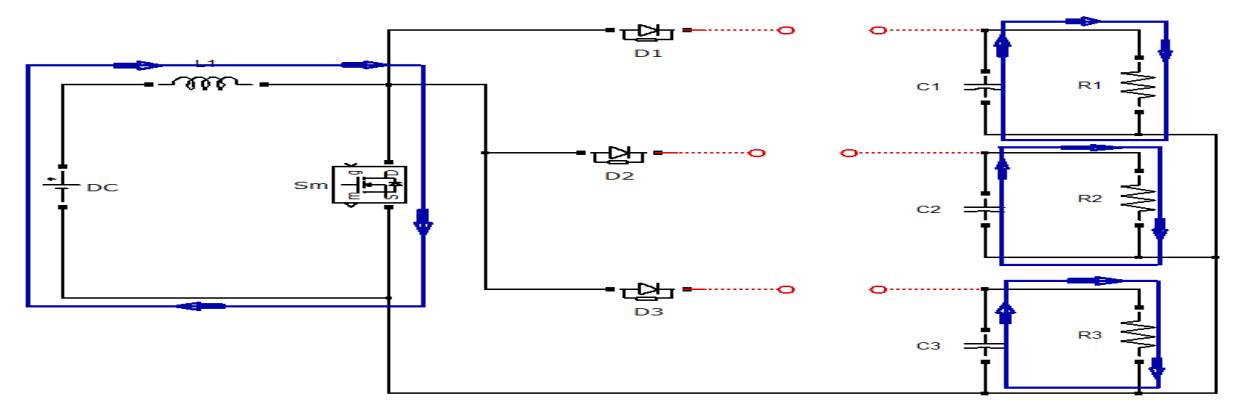

Fig. 4 Modes of operation, 4a) Mode 1 


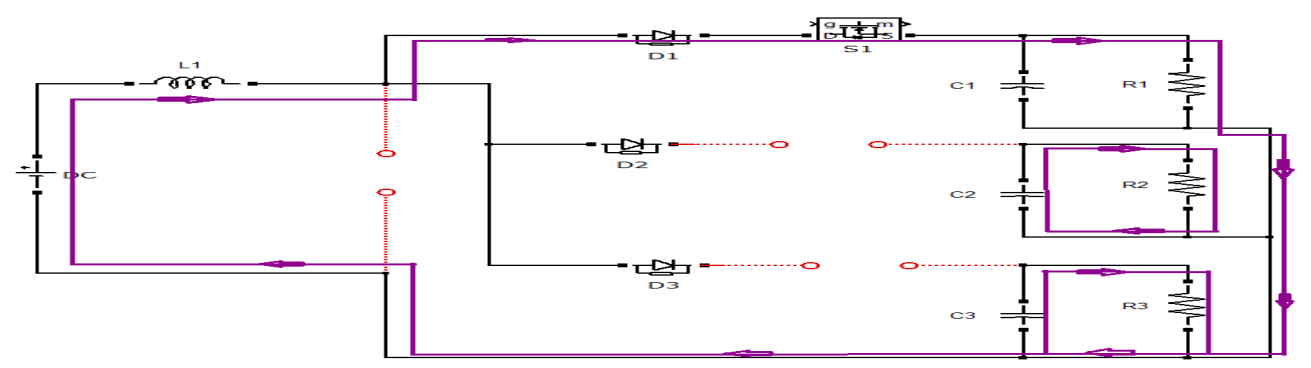

Fig. 4b) Mode 2

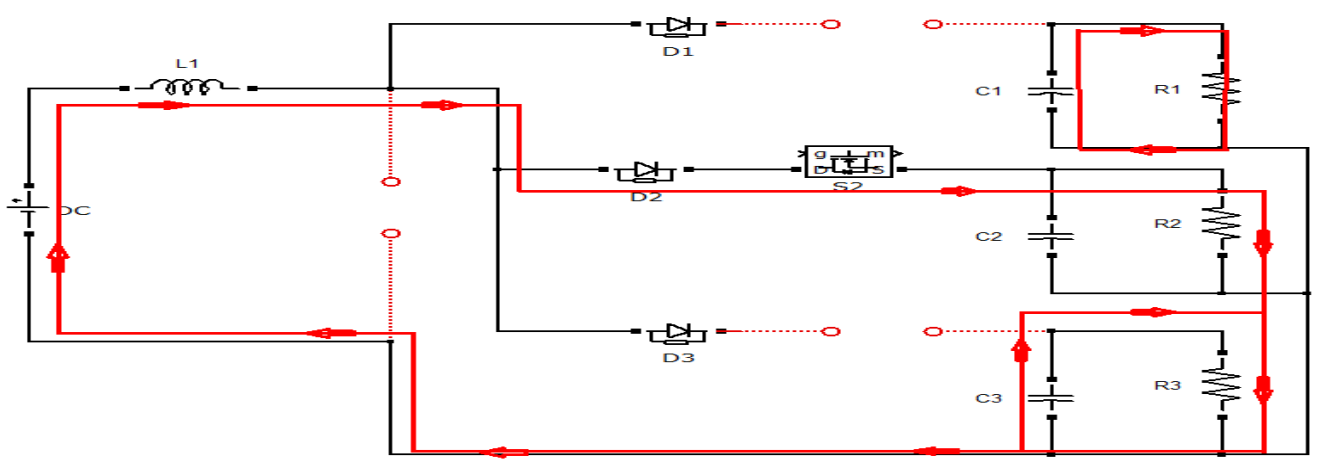

Fig. 4c) Mode 3

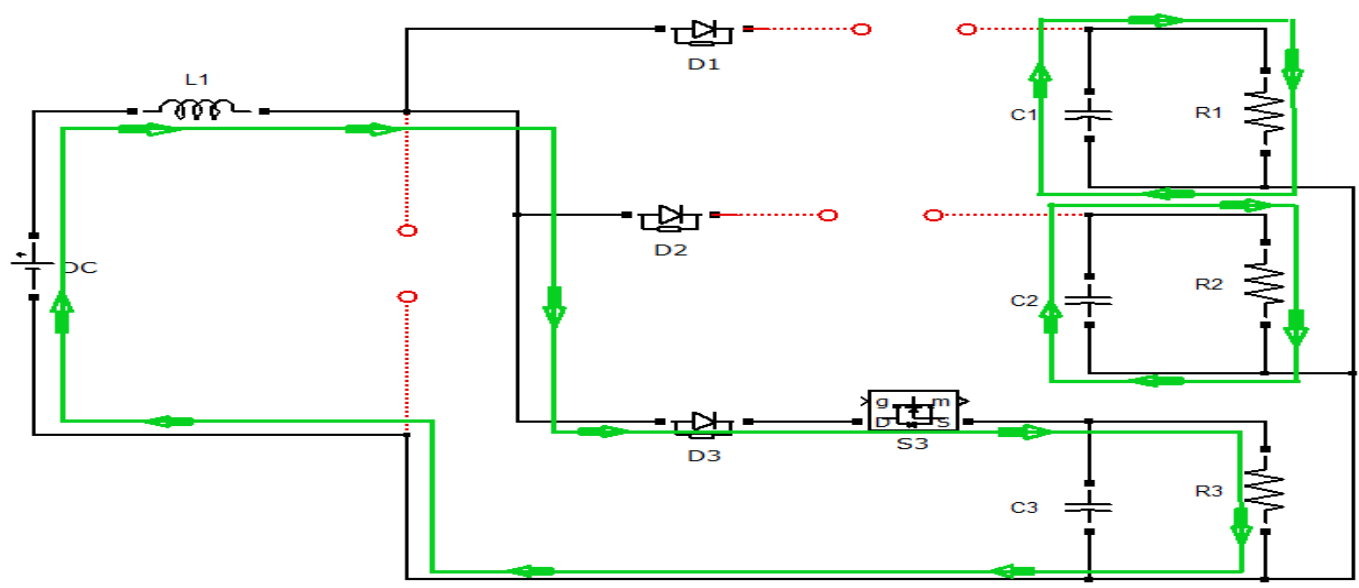

Fig. 4d) Mode 4

Fig. 5 shows the sequence of the switching conduction. In the first switching period, the high side switches turn on in the sequence of $\mathrm{S} 1 \rightarrow \mathrm{S} 2 \rightarrow \mathrm{S} 3 \rightarrow \mathrm{S} 1$. Note that the S1 switch turns on twice in that period. In the next switching period, the conduction resumes from S2, and the sequence becomes $\mathrm{S} 2 \rightarrow \mathrm{S} 3 \rightarrow \mathrm{S} 1 \rightarrow \mathrm{S} 2$. Following this rule, the next sequence is $\mathrm{S} 3 \rightarrow \mathrm{S} 1 \rightarrow \mathrm{S} 2 \rightarrow \mathrm{S} 3$ and subsequently back to the original $\mathrm{S} 1 \rightarrow \mathrm{S} 2 \rightarrow \mathrm{S} 3 \rightarrow$ $\mathrm{S} 1$. The digital controller that generates such sequences is simple and can be easily extended to the case with an arbitrary N. Per-mutating the conduction sequence this way can reduce the systematic differences among the LED channel currents due to current/voltage ripples.

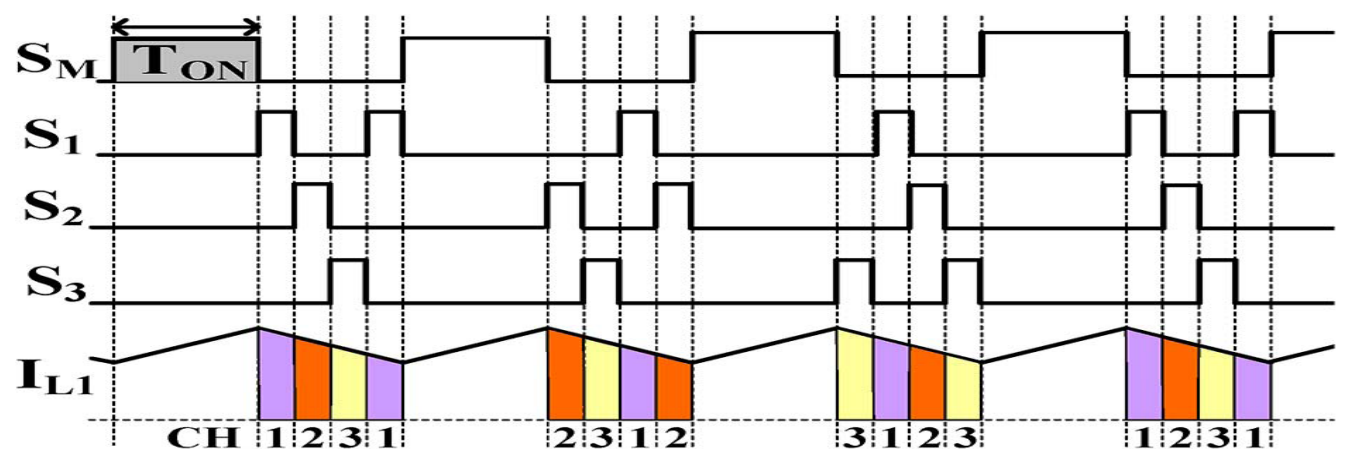

Fig. 5 Timing diagram (time-division multiplexing control when the number of channels $(\mathrm{N})$ is 3.) 


\section{SIMULATION RESULTS}

Fig 6 shows the dc input of the conventional converter. Fig 7 and Fig 8 shows the gate pulse, current and voltage across switch S1 and S2. The current and voltage across switch on and off is in zero condition. Fig 9 shows the Gate pulse and current through inductor $\mathrm{L}_{\mathrm{m}}$ and $\mathrm{L}_{\mathrm{r}}$. Fig10 shows the Gate pulse, current and voltage across capacitor $\mathrm{C}_{\mathrm{r}}$. Fig 11 shows the Gate pulse and current through transformer primary and secondary side. From the figure, current is sinusoidal shape. Fig 12 shows the multi output voltage

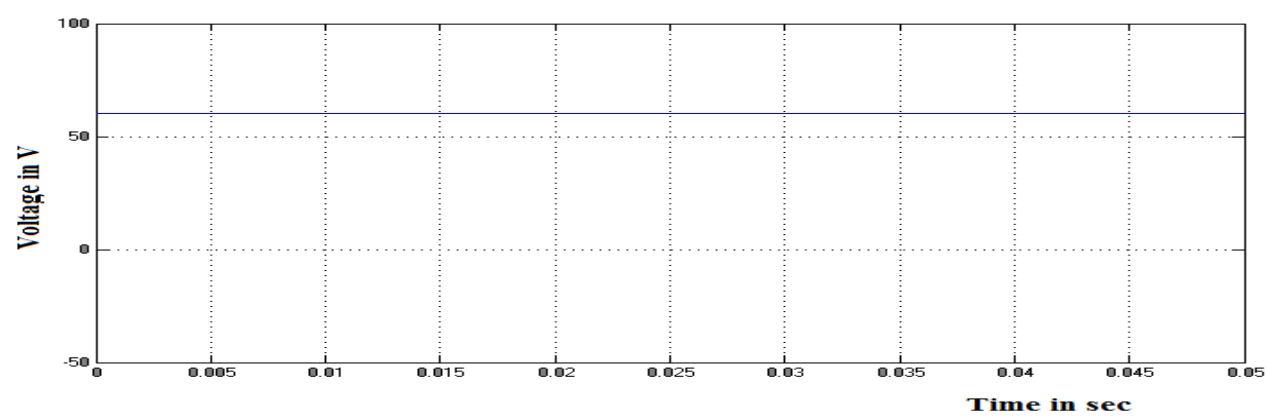

Fig. 6 Dc input voltage
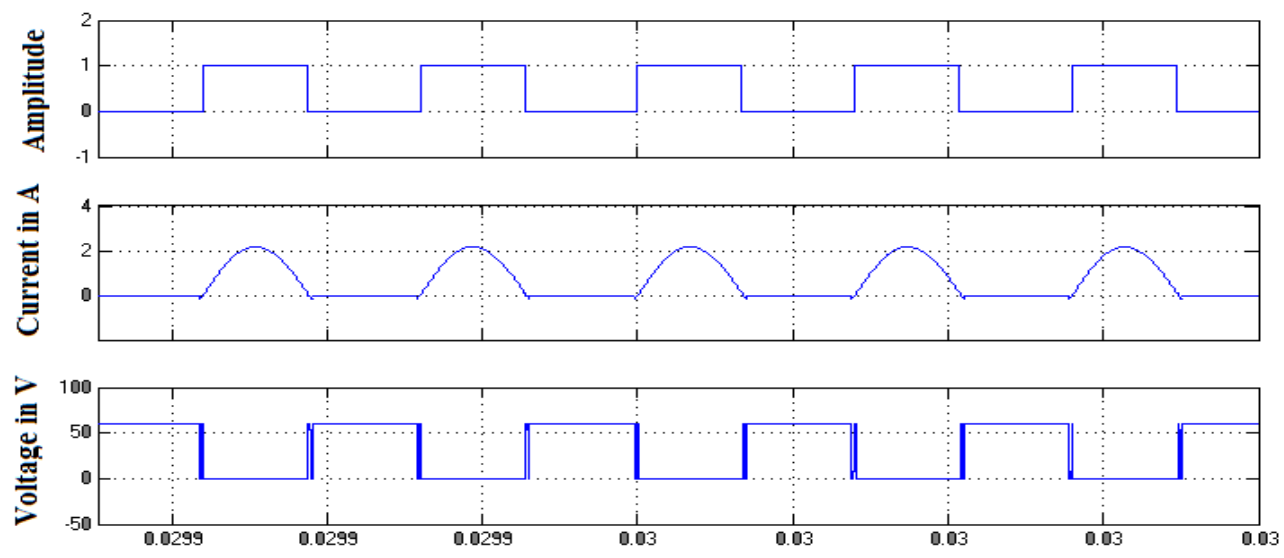

Time in sec

Fig. 7 Gate pulse, current and voltage across switch S1

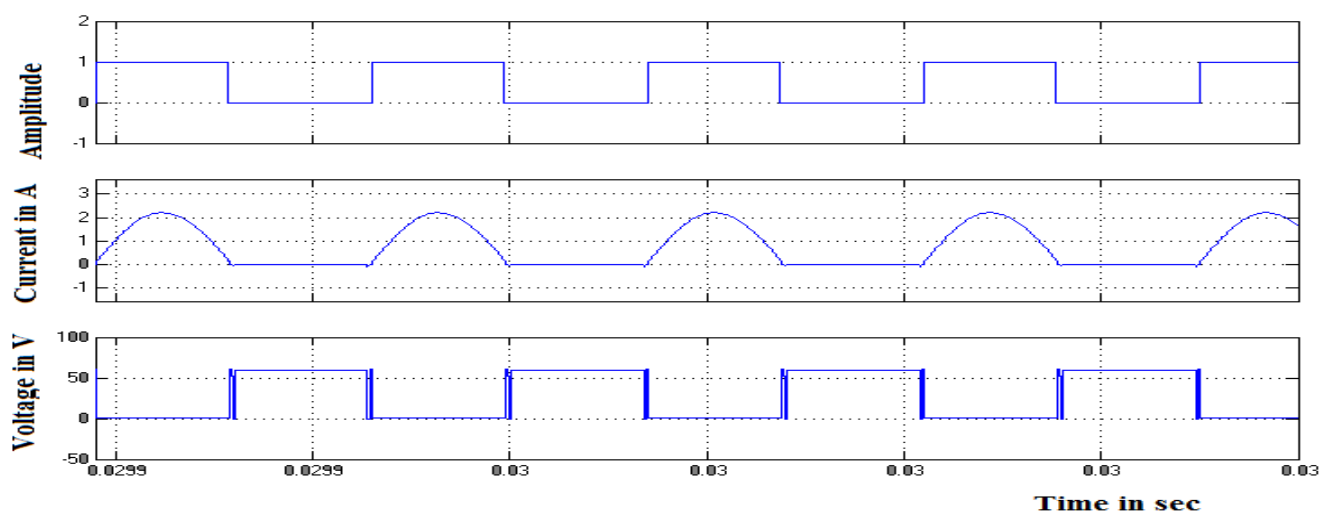

Fig. 8 Gate pulse, current and voltage across switch S2 

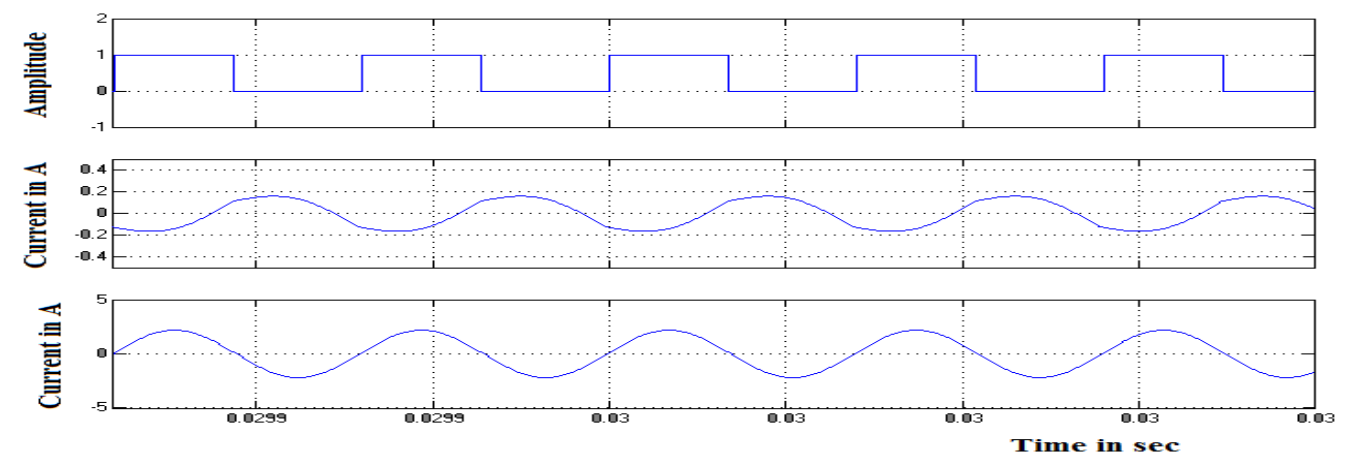

Fig. 9 Gate pulse and current through inductor $\mathrm{L}_{\mathrm{m}}, \mathrm{L}_{\mathrm{r}}$
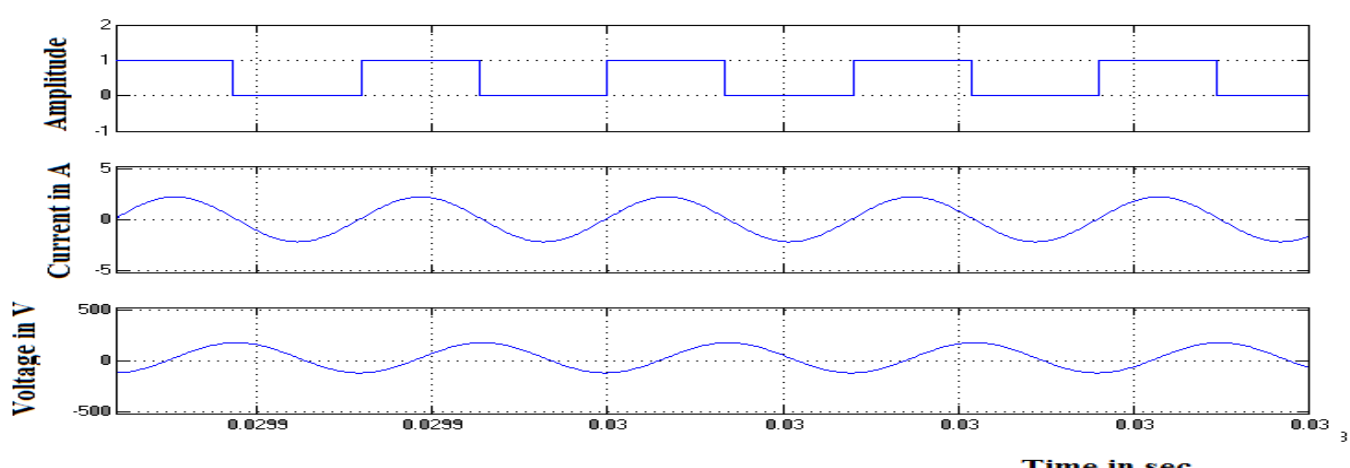

Fig. 10 Gate pulse, current and voltage across capacitor $\mathrm{C}_{\mathrm{r}}$
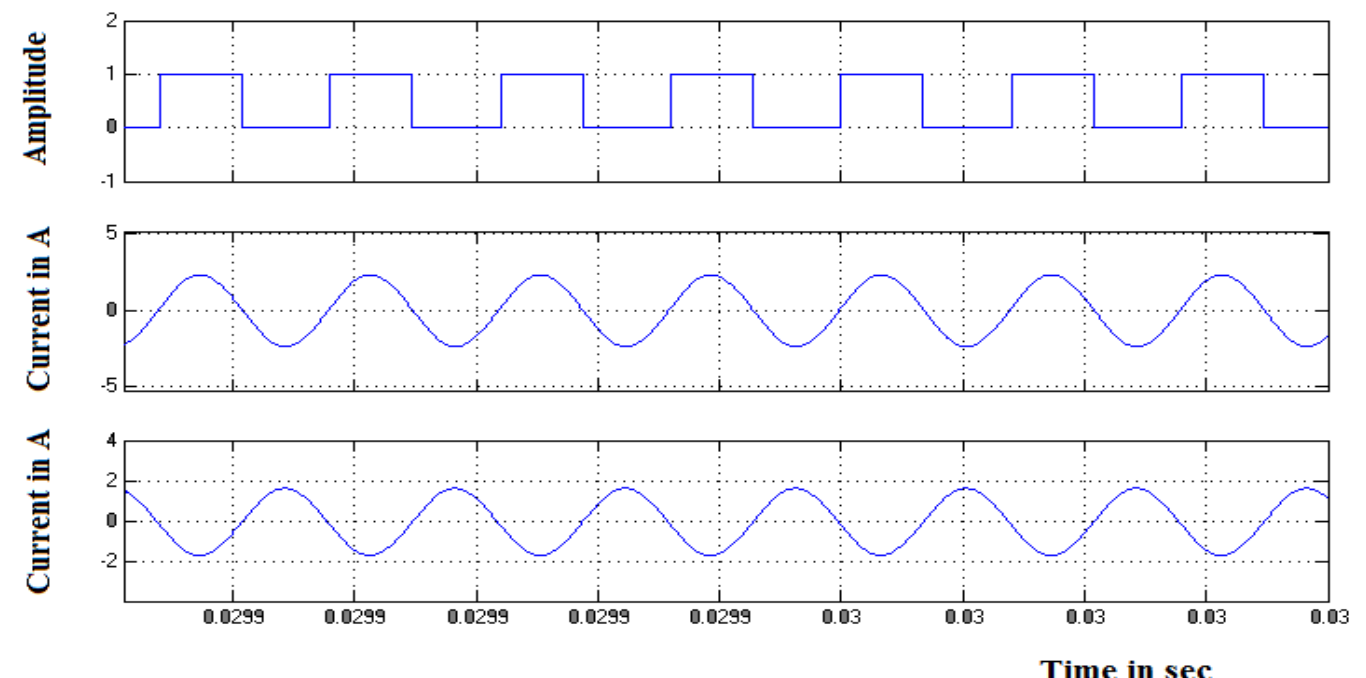

Fig. 11 Gate pulse and current through transformer primary and secondary side winding 

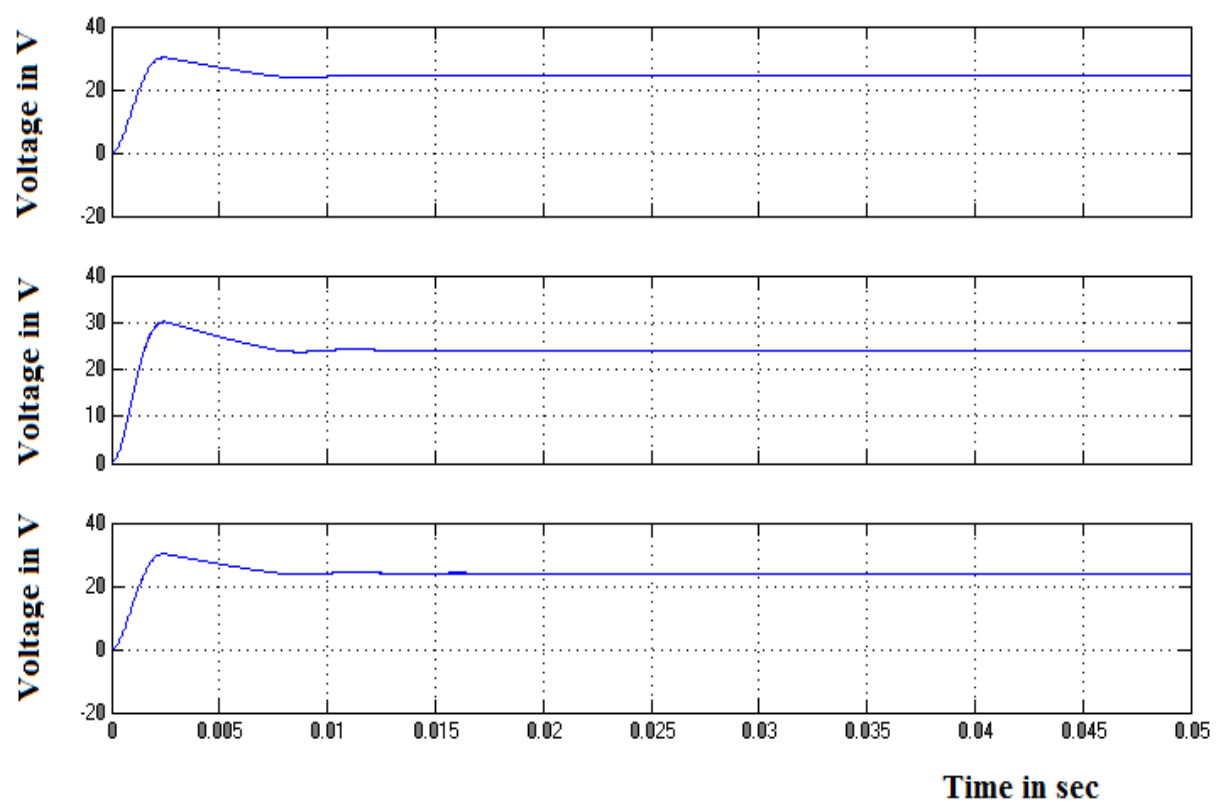

Fig .12 Three output voltage for LLCC resonant converter

Fig13 Shows the Input voltage of the proposed converter. Fig 14 Shows the Pulse generation circuit. Fig15 shows the Triggering pulses pattern for power switches. Fig16 shows the gate pulse and current through boost inductor. Fig 17, 18 and 19 shows the gate pulse current through and voltage across switch S1, S2 and S3 respectively. Fig 20 shows the output voltage of the converter.

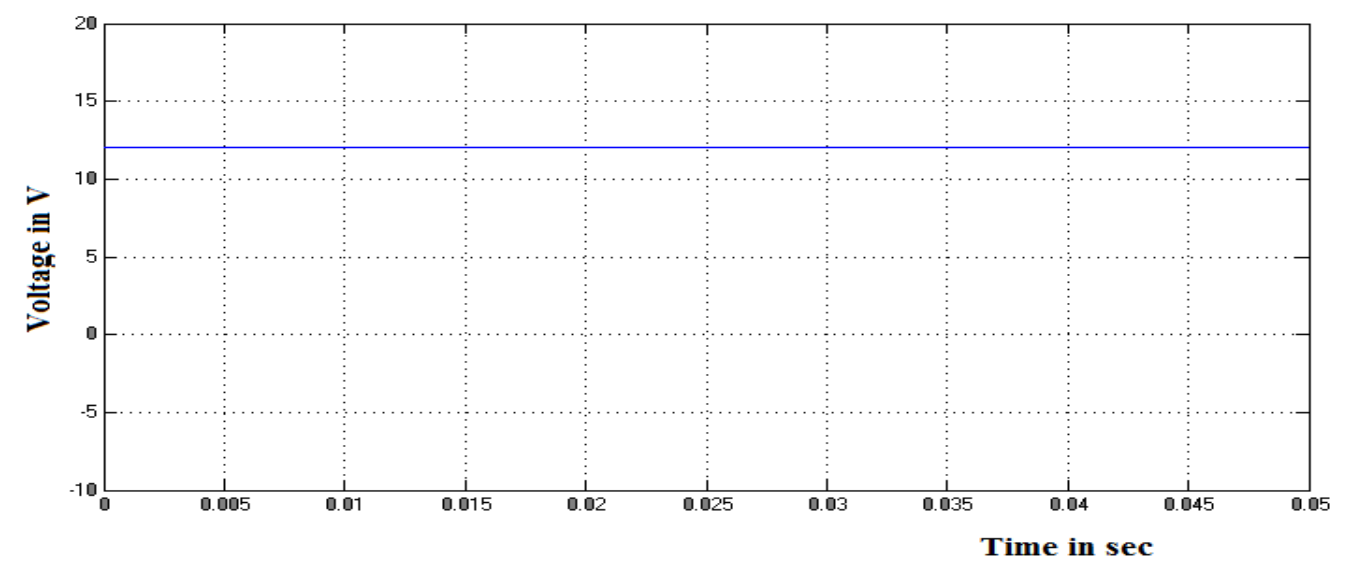

Fig .13 Input voltages

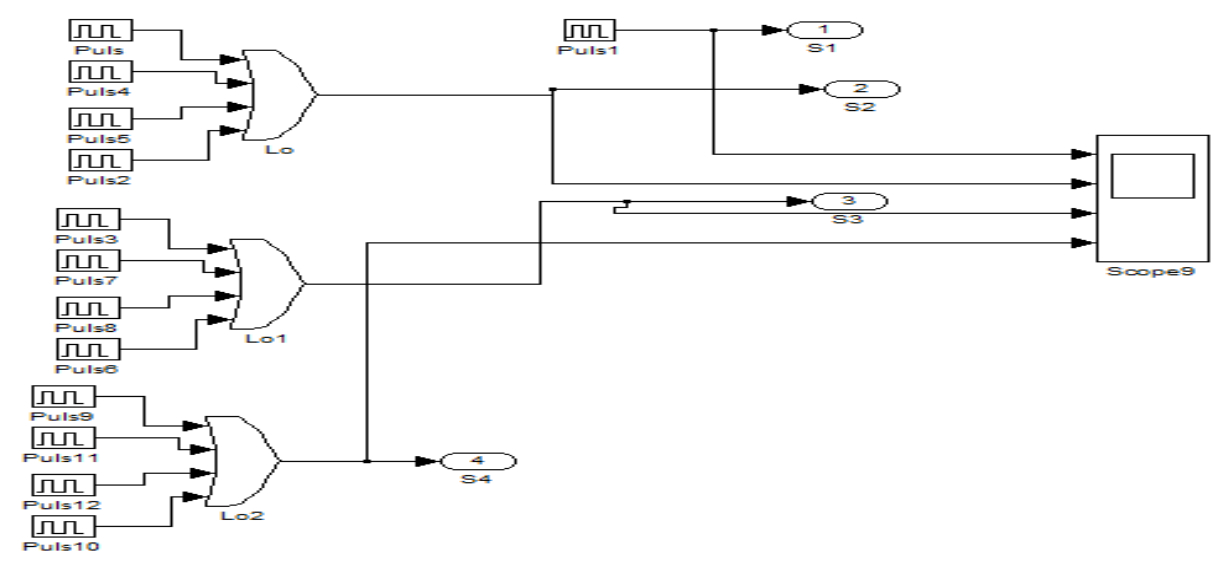

Fig .14 Pulse Generation Circuit 


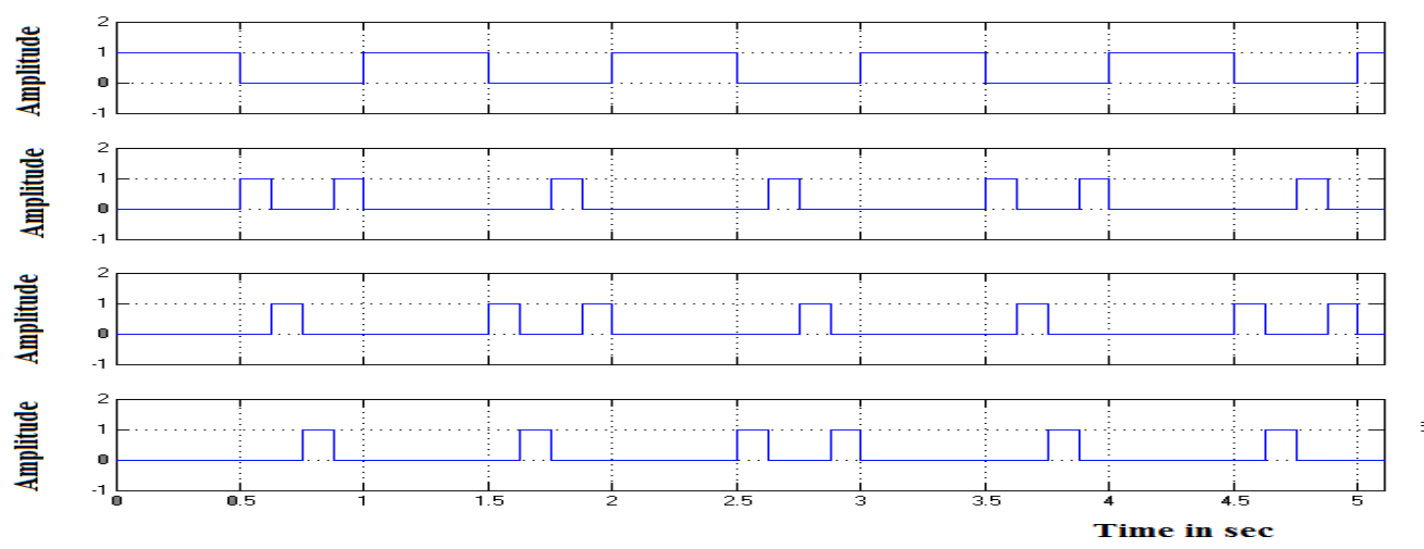

Fig .15 TRIGGERING PULSES FOR SWITCHES
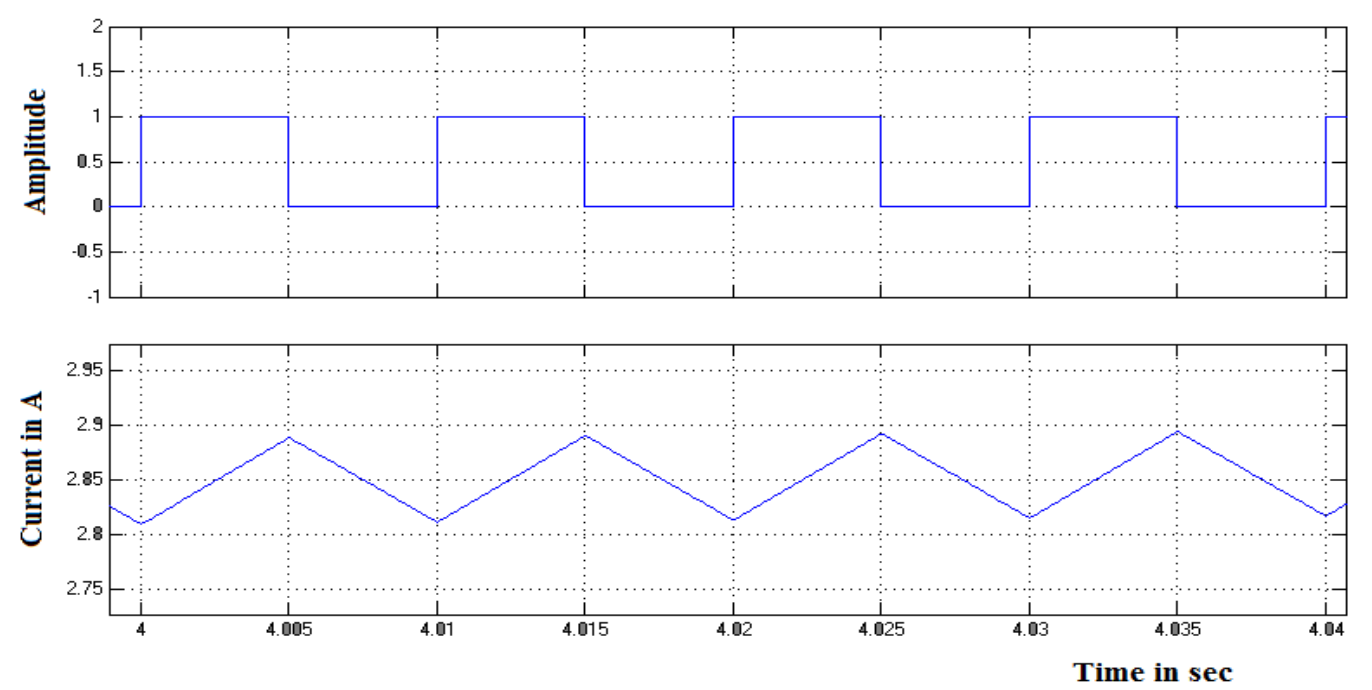

Fig .16 BOOST CONVERTER GATE PULSE AND CURRENT THROUGH INDUCTOR
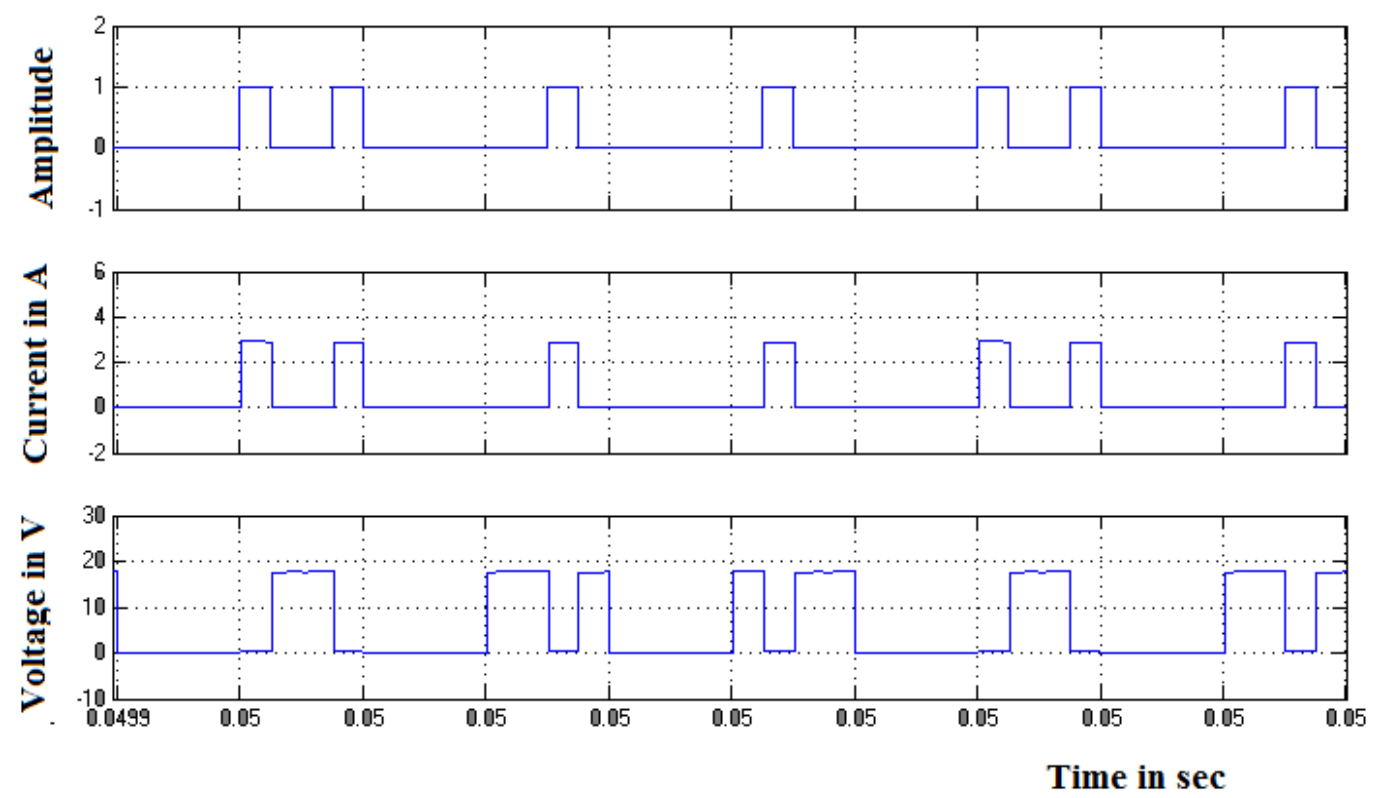

Fig .17 Gate pulse, drain current and voltage across switch S1 

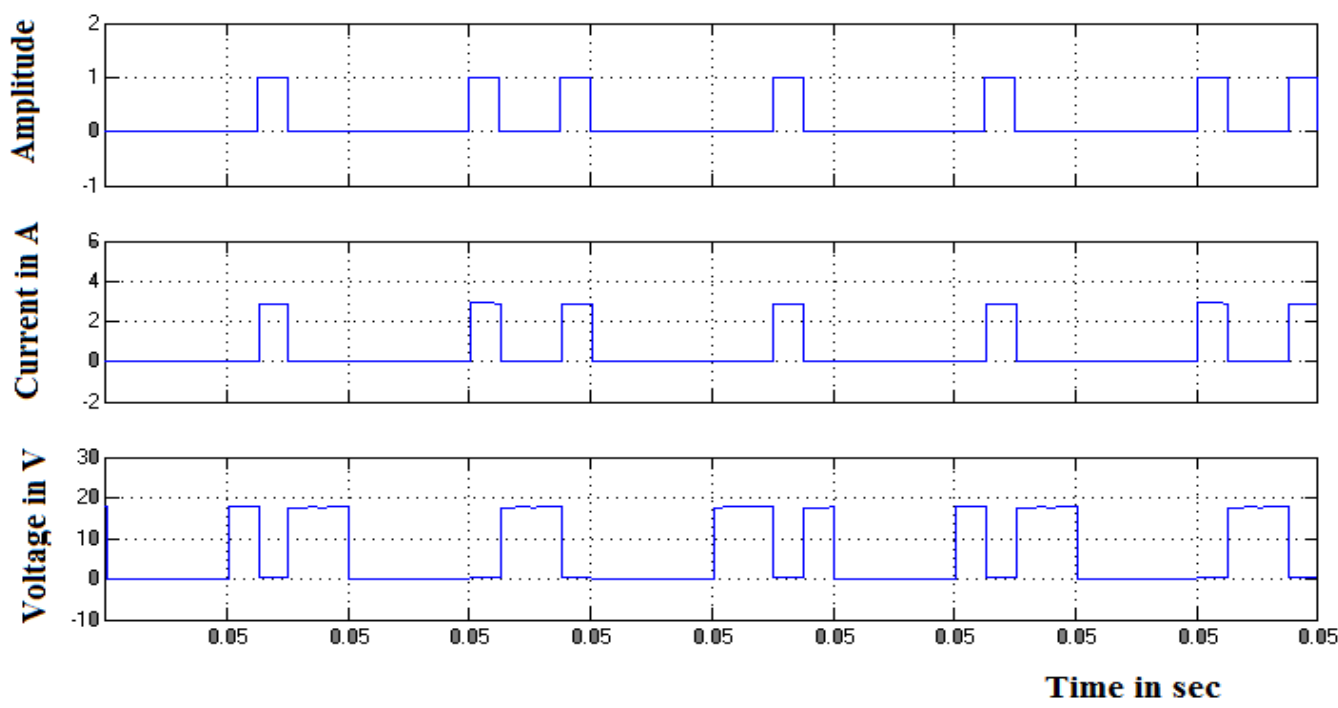

Fig .18 Gate pulse, drain current and voltage across switch S2
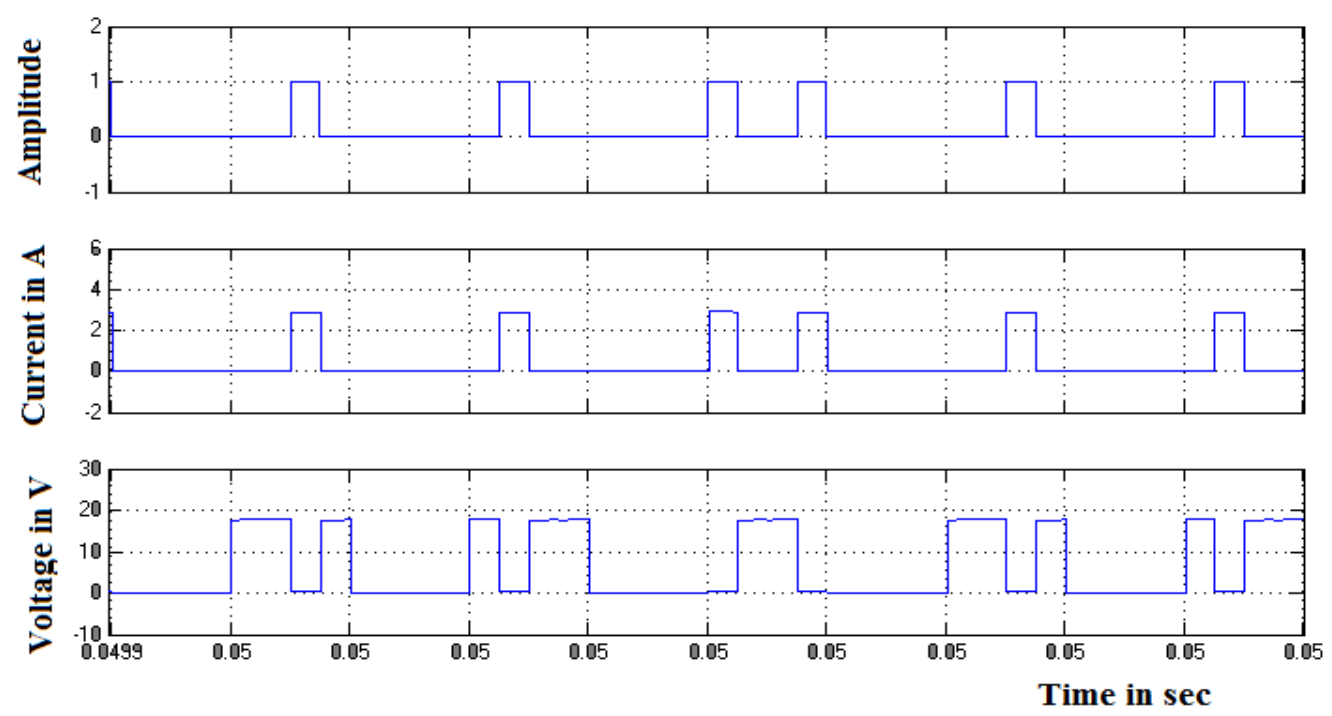

Fig .19 Gate pulse, drain current and voltage across switch S3 

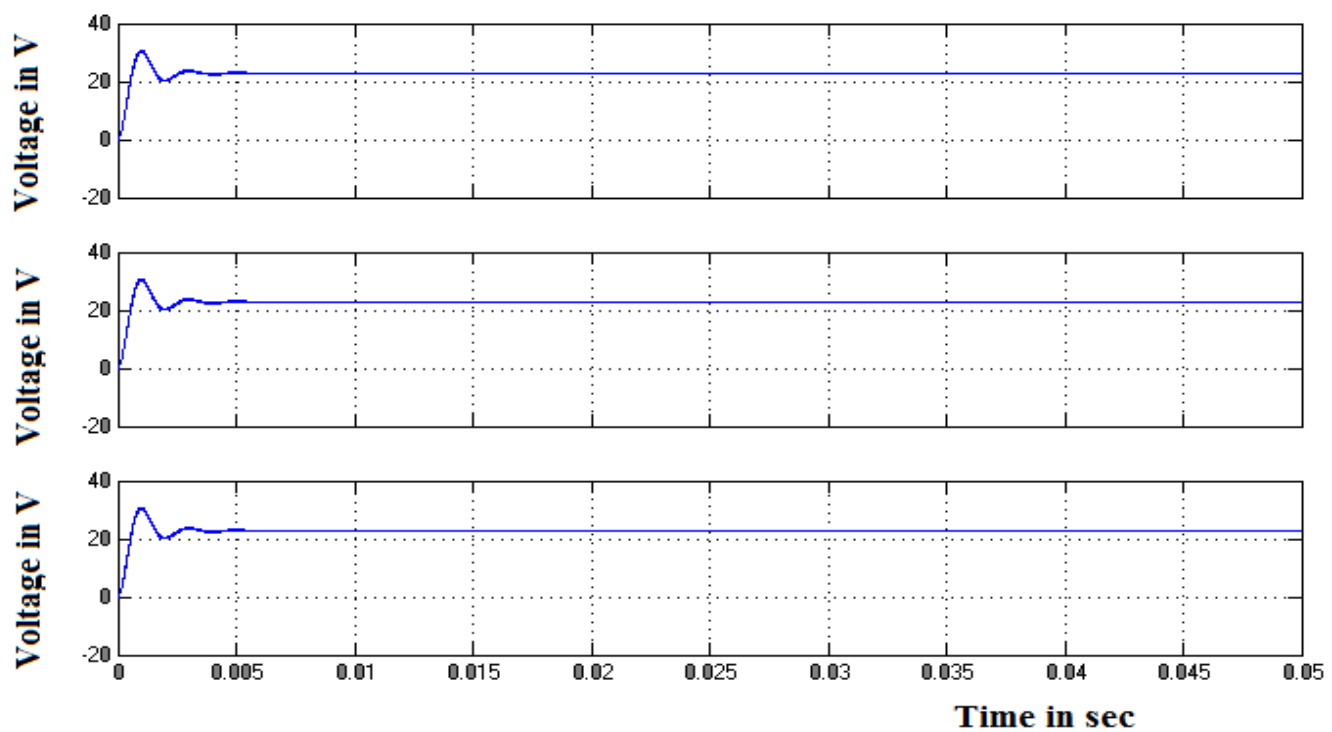

Fig .20 Three output voltage for converter

\section{COMPARATIVE ANALYSIS}

LLCC resonant inverter based multi output converter and single inductor boost converter based multi output converter circuit are simulated using MATLAB. The performance parameter is as shown in Table- 1 . Both converters are designed for each output $24 \mathrm{~V}$ and $12 \mathrm{~W}$. The single inductor multi output converter has higher efficiency compared to LLCC converter, it is shown from Table-1 and Fig 21.

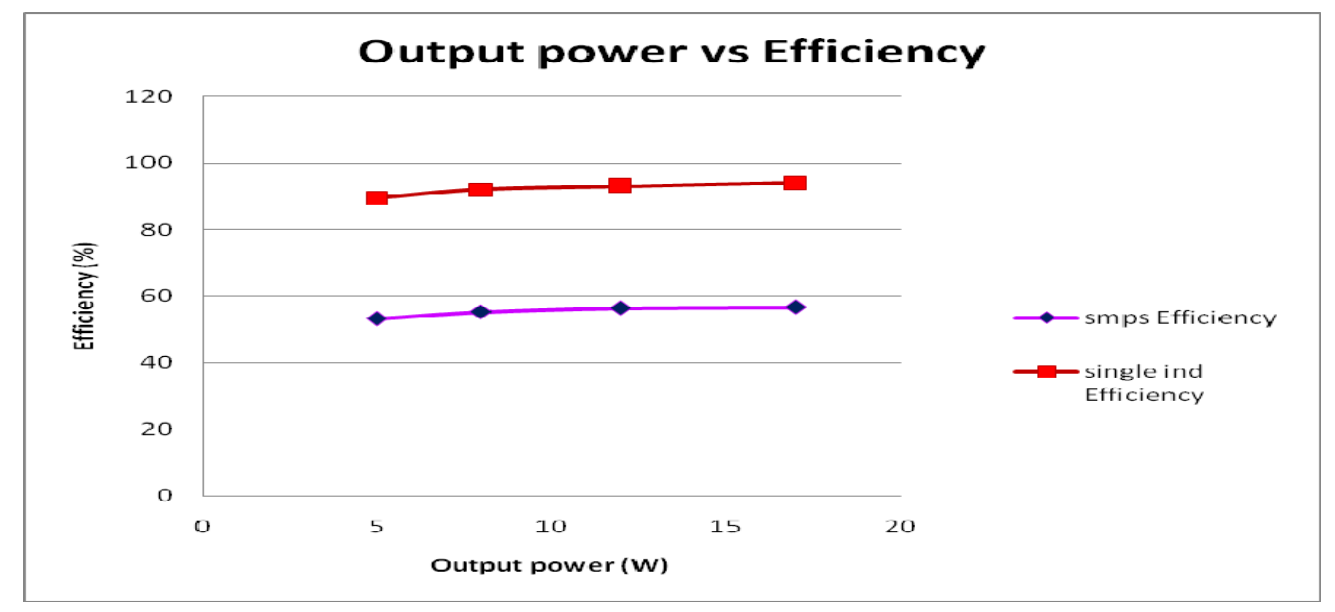

Fig .21 Efficiency Graph

Table-1

\begin{tabular}{|c|c|c|}
\hline Parameters & LLCC converter & Single inductor converter \\
\hline Input voltage & $60 \mathrm{~V}$ & $12 \mathrm{~V}$ \\
\hline Each Output voltage & $24 \mathrm{~V}$ & $23.5 \mathrm{~V}$ \\
\hline Output power & $36 \mathrm{~W}$ & $35 \mathrm{~W}$ \\
\hline Efficiency & $54.5 \%$ & $94.1 \%$ \\
\hline
\end{tabular}

\section{CONCLUSION}

In this paper, resonant based multi output converter and single inductor boost based multi output converter is presented. Both circuits achieve equal current sharing, for each channels using different concept. The resonant converter has more devices compared to boost converter, as a result the resonant converter has more conduction loss and less efficiency. It is proved from simulation results. From this analysis, the single inductor boost based multi output converter is most suitable for low power applications and cost effective. 


\section{REFERENCES}

[1] Y.K. Cheng, K.W.E. Cheng, "General Study for using LED to replace traditional lighting devices," In Proc. 2nd International Conference on Power Electronics Systems and Applications, 2006. ICPESA '06., pp.173-177, 12-14.

[2] M. Krames, O. Shchekin, R. Mueller-Mach, G. Mueller, L. Zhou, G. Harbers, and M. Craford, "Status and future of high-power light emitting diodes for solid-state lighting,” Display Technol. J., vol. 3, no. 2, pp. 160-175, Jun. 2007.

[3] Yan-Cun Li; Chern-Lin Chen "A Novel Single-Stage High-Power-Factor AC-to-DC LED Driving Circuit With Leakage Inductance Energy Recycling" IEEE Transactions on Industrial Electronics, Vol: 59 , No. 2. Page(s): 793 -802. Feb. 2012,

[4] C. Chen, C. Wu, Y. Chen, and T. Wu, "Sequential Color LED Backlight Driving System for LCD Panels" IEEE Trans. on Power Electron., vol. 22, no. 3, pp. 919-925, May. 2007.

[5] H. Chiu, S. Cheng "LED Backlight Driving System for Large-Scale LCD Panels," IEEE Trans. on Ind. Electron., vol. 54, no. 5, pp. 2751-2760, Oct. 2007.

[6] Y.Hu, M. Jovanovic. "LED driver with self-adaptive drive voltage". IEEE Trans. on Power Electron., vol.23 no.11. Pp.3116-3125. Mar. 2008.

[7] S.K. Ng; K.H. Loo,; S.K. Ip,; Y.M. ; C.K. Tse,; K.T. Mok, "Sequential Variable Bilevel Driving Approach Suitable for Use in HighColor-Precision LED Display Panels" IEEE Trans. On Industrial Electronics, Vol. 59 , no. 12 Page(s): 4637 - 4645, Dec. 2012.

[8] S. Li; Z. .W.X. Zhong, W. Chen, and S.Y.R Hui. "Novel Self-Configurable Current-Mirror Techniques for Reducing Current Imbalance in Parallel Light-Emitting Diode (LED) Strings," IEEE Trans. on Power Electron., vol. 27, no. 4, pp. 2153-2162, April. 2012.

[9] Xinke $\mathrm{Wu}$, Chen Hu, Junming Zhang, and Zhaoming Qian. "Analysis and Design Considerations of LLCC Resonant Multi-Output Dc/Dc LED Driver with Charge Balancing and Exchanging of Secondary Series Resonant Capacitors," 2015 IEEE Transactions on Power Electronics

[10] Y. Hu and M. M. Javanovic, "LED Driver with self-adaptive drive voltage,” IEEE Trans. Power Electron., vol. 23, no. 6, pp. $3116-$ 3125 , Nov. 2008.

[11] K. Yao and J. C. Moyer, "Control of multi-string LED array,” U.S. Patent 0148 323, Jun. 23, 23.

[12] Hyun-Chang Kim, Chang Soo Yoon, Deog-Kyoon Jeong and Jaeha Kim. "A Single-Inductor, Multiple-Channel Current-Balancing LED Driver for Display Backlight Applications," IEEE transactions on industry applications, vol. 50, no. 6, november/december 2014.

\section{Author's details}

Santhi Mary Antony A obtained her B.E. degree from University of Madras, Chennai in the year 2003, M.E. degree from Sathyabama University, Chennai in the year 2005. She is currently pursuing her research in power electronics in Sathyabama University. She has more than ten years of academic experience. She is currently working as Asst. Professor in the Department of EEE, Sathyabama University, Chennai. 